\title{
Testing technologies and strategies for exploration in Australian Mars analogues: A review
}

\author{
Michael D. West ${ }^{\text {a,b,* }}$, Jonathan D.A. Clarke ${ }^{\mathrm{c}, \mathrm{d}}$, Jennifer H. Laing ${ }^{\mathrm{e}, \mathrm{d}}$, David Willson ${ }^{\text {f,d }}$, James M.A. Waldie ${ }^{\mathrm{d}}$, \\ Guy M. Murphy ${ }^{\mathrm{d}}$, Matilda Thomas ${ }^{\mathrm{c}}$, Graham A. Mann ${ }^{\mathrm{g}, \mathrm{d}}$ \\ ${ }^{a}$ Research School of Physics and Engineering, The Australian National University, Canberra, ACT 0200, Australia \\ b Mars Institute, NASA Research Park, Moffett Field, CA 94035-0006, USA \\ c Australian Centre for Astrobiology, University of New South Wales, Sydney, NSW 2052, Australia \\ ${ }^{\mathrm{d}}$ Mars Society Australia, P.O. Box 327, Clifton Hill, VIC 3068, Australia \\ e Tourism Research Unit, Monash University, PO Box 1071, Narre Warren, VIC 3805, Australia \\ ${ }^{\mathrm{f}}$ Tenova SEMF, 2nd Floor, 45 Murray Street, Hobart, TAS 7000, Australia \\ ${ }^{\mathrm{g}}$ School of Information Technology, Murdoch University, South Street, Murdoch, WA 6150, Australia
}

\section{A R T I C L E I N F O}

\section{Article history:}

Received 1 February 2009

Received in revised form

23 September 2009

Accepted 25 September 2009

Available online 8 October 2009

\section{Keywords:}

Australia

Mars analogues

Space habitats

Space suits

Pressurized surface vehicles

Human factors

Education and public outreach

\begin{abstract}
A B S T R A C T
Australia is an ideal testing ground in preparation for the robotic and human exploration of Mars. Numerous sites with landforms or processes analogous to those on Mars are present and the deserts of central Australia provide a range of locations for free-ranging Mars analogue mission simulations. The latest developments in testing technologies and strategies for exploration in Australian Mars analogues are reviewed. These include trials of analogue space suits based on mechanical counter pressure technology and the development of an analogue, crewed, pressurized rover for long-range exploration. Field science activities and instrumentation testing relevant to robotic and future crewed missions are discussed. Australian-led human factors research undertaken during expeditions to Mars analogue research stations and expeditions to Antarctica are also reviewed. Education and public outreach activities related to Mars analogue research in Australia are also detailed.
\end{abstract}

(c) 2009 Elsevier Ltd. All rights reserved.

\section{Introduction}

Given the risks, costs and complexities associated with human missions to Mars, analogue research can be a powerful tool to explore the challenges associated with and prepare for living, operating and undertaking research upon another planet. Simulations of planetary surface operations, tests of technologies and strategies for exploration and personnel training exercises will provide valuable data and experiences for mission planners, engineers and planetary scientists. To date, various locations around the world have been used as Mars analogues, at varying levels of fidelity, in the support of current and future robotic and future human missions (Lee and Osinski, 2005).

For decades, visitors to central Australia have marvelled at its likeness to Mars and recent motion pictures have used footage from various locations, including around Coober Pedy, to portray

\footnotetext{
* Corresponding author at: Research School of Physics and Engineering, The Australian National University, Canberra, ACT 0200, Australia.

E-mail addresses: michael.west@anu.edu.au (M.D. West), jon.clarke@bigpond. com.au (J.D.A. Clarke)
}

the surface of the Red Planet. The regolith of central Australia, with its abundance of oxidized iron-bearing minerals, bears visual and compositional similarities to martian regolith. Moreover, geologically, Australia has much to offer researchers interested in Earth analogues of both ancient and modern environments on Mars. The ancient terrains and arid regions of central Australia have preserved many desert landforms, impact structures and hydrothermal systems that provide a useful reference for interpreting the results provided by spacecraft orbiting Mars and exploring the martian surface. Australia also has examples of acid lakes, hypersaline embayments, mound springs, relief inversion and many other geological processes and features that are of Mars analogue value (West et al., 2010).

Central Australia's deserts are also one of the best locations for free-ranging Mars analogue mission simulations. Unlike other widely used Mars analogue sites, for example Devon Island, Rio Tinto, Iceland, the Atacama desert and the region near Hanksville, Utah; central Australia has large and isolated test areas on the scale of hundreds of kilometres that can be used for testing a suite of realistic analogue hardware and logistics, such as crewed rover vehicles and communications systems. Australia also has a stable political situation, excellent local infrastructure and modern 
services and a tolerable climate. Various orbiting and airborne instruments have imaged the country in detail and due to the isolation of the areas of interest, land use is minimal. Australia has a strong educational system, an industrial sector renowned for its innovation and ingenuity and a scientific community well versed in planetary science and space engineering. Many researchers have extensive experience operating in the arid interior, the continent is serviced by an emergency air evacuation service and Australia has a long history of operations in isolated locations, such as mining outposts, remote cattle stations and in Antarctica.

In this paper, the testing of technologies and strategies for Mars exploration in Australia's analogue sites are discussed. The principal Mars analogue regions are reviewed and the latest developments in analogue Mars habitat, space suit and pressurized rover vehicle research is outlined. Field science activities and instrumentation testing in support of robotic missions are also highlighted along with human factors research, including that undertaken in Antarctica. The education and public outreach activities that have been undertaken in Australia and are related to Mars analogue research are reviewed and future opportunities are also identified. The geology of Australia's various landforms that have Mars analogue value and specific Mars analogue sites are reviewed in a companion work (West et al., 2010).

\section{Principal Mars analogue regions}

Mars analogue research in Australia has generally been focussed around two locations, the Arkaroola region of South Australia and the Pilbara region in north-western Western Australia. During late 2001 an extensive survey of several locations in South Australia and the Northern Territory was conducted (Mann et al., 2004a) to assess their value as Mars analogues and to select a site for the establishment of the proposed Australian Mars Analogue Research Station (MARS-Oz). As shown in Fig. 1, six candidate regions were identified by Mars Society Australia (MSA). Figs. 2-7 show some of the Mars-like terrains at each of these locations. MSA is an Australian not-forprofit research and education organization, linked with the international Mars Society, that is dedicated to promoting the exploration of Mars.

The Arkaroola Mars Analogue Region (AMAR) is located in the northern Flinders Ranges of South Australia and is adjacent to the Mt Painter Wildlife Sanctuary. Many notable Mars analogue landscape features can be found: to the north are the dune fields and gibber plains of the Strzelecki and Sturt Stony Deserts (Fig. 6), to the east and north west the dry salt lakes of Lake Frome and Lake Eyre, respectively, and to the west the rugged bedrock exposures of the Adelaide Fold Belt (Fig. 7) and ancient hydrothermal systems of Mt Painter and Mt Gee (Clarke et al., 2004). The geological value of the AMAR as a Mars analogue has been recently reviewed by West et al. (2010) and the features present differ markedly from those found in other analogue locations.

The AMAR is accessible by road and air, via a nearby all weather runway, yet is very isolated from the outside world. The nearest major city, Adelaide, is a $12 \mathrm{~h}$ drive south and the nearest regional centre is Port Augusta, which is a $9 \mathrm{~h}$ drive away. The diverse landscapes of the region also allow for the testing of equipment and exploration strategies in a variety of environments and terrains. Compared with other Mars analogue sites, such as Devon Island, Iceland or Utah, the AMAR is not spatially constrained by land tenure issues. Traverses of tens of kilometres are possible with only limited interaction with other human activities. Longer range traverses of hundreds of kilometres are also possible if dirt roads are used.

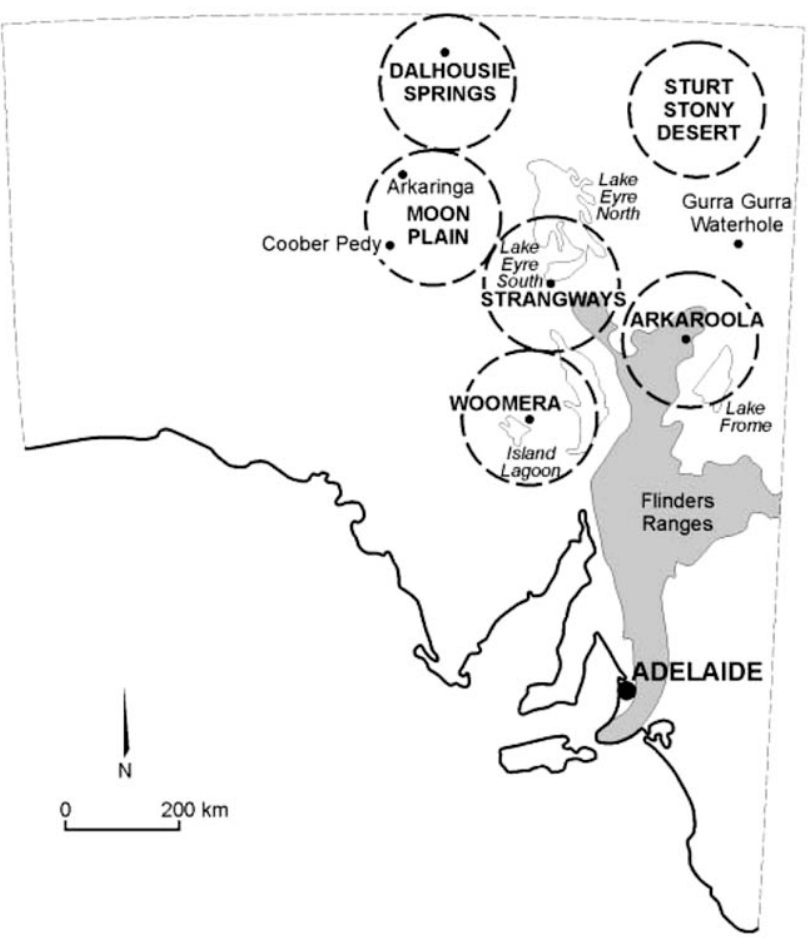

Fig. 1. The six $200 \mathrm{~km}$ diameter Mars analogue exploration zones identified during the 2001 Jarntimarra expedition (Mann et al., 2004a) including the Arkaroola Mars Analogue Region of the northern Flinders Ranges.

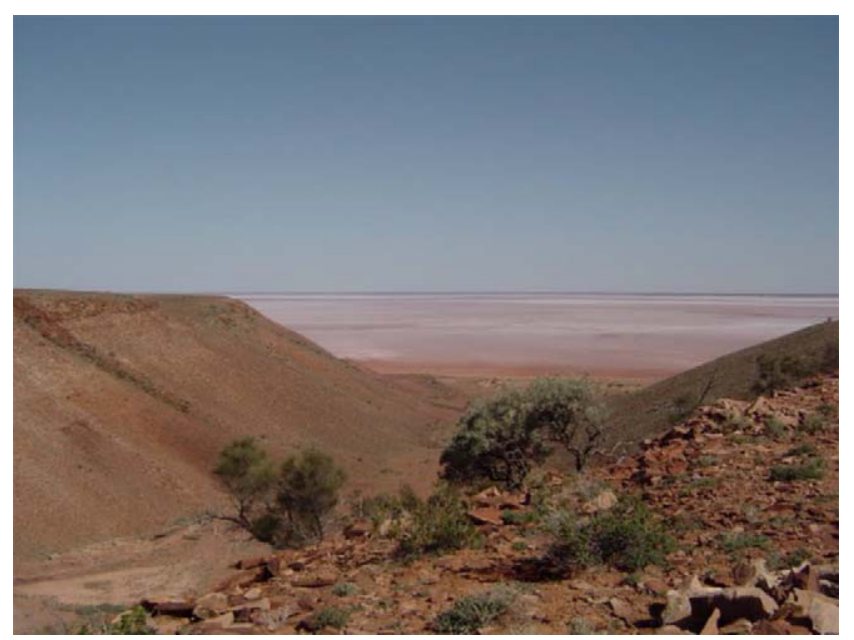

Fig. 2. Looking over Island Lagoon located in the Woomera exploration zone: $31^{\circ} 19^{\prime} 46.78^{\prime \prime} \mathrm{S} 136^{\circ} 28^{\prime} 45.46^{\prime \prime} \mathrm{E}$.

The Pilbara region has long been recognized for its significance as a Mars analogue. The geological characteristics of this region that are of relevance to Mars analogue research have been summarized recently (West et al., 2010) and are only noted in brief here. The Pilbara Craton is one of the oldest (3.2-3.5 Ga) and best preserved sedimentary and volcanic successions in the world. The volcanic successions have been suggested as a possible analogue for the flood basalts of Mars (Brown, 2004). The region contains one of the best studied and largest hydrothermal system on Earth and the earliest convincing evidence of life is recorded in the biosignatures found in the abundant stromatolites, microfossils and isotopic signatures at North Pole Dome (Schopf et al., 2007; Walter et al., 1980; Allwood et al., 2006; Van Kranendonk, 2006). The minimal vegetation cover and oxidized 


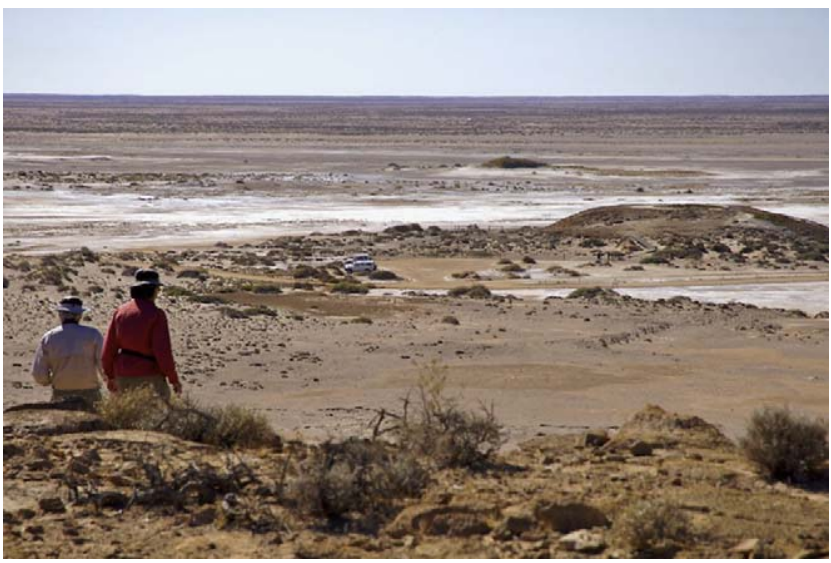

Fig. 3. The Strangways Springs complex located in the Strangways exploration zone: $29^{\circ} 08^{\prime} 45.92^{\prime \prime} \mathrm{S} 136^{\circ} 34^{\prime} 11.59^{\prime \prime} \mathrm{E}$

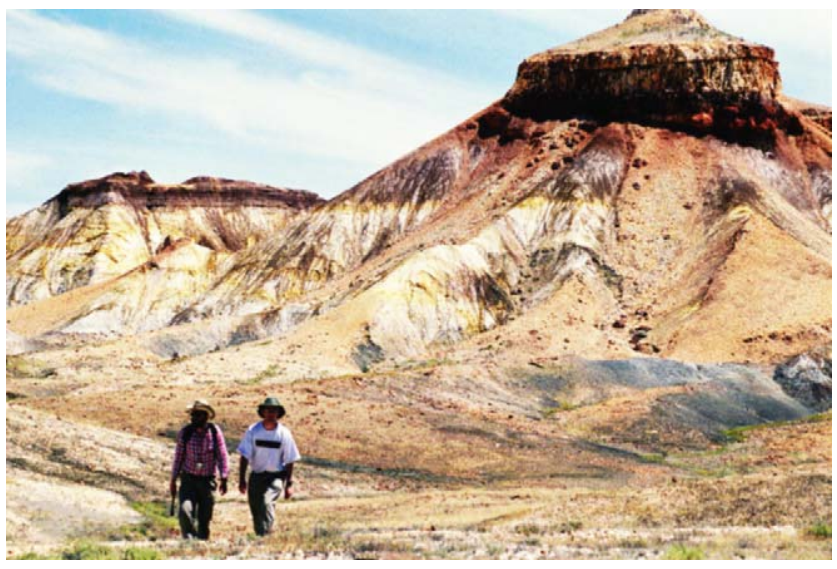

Fig. 4. The mesas of the Painted Desert near Arkaringa located in the Moon Plain exploration zone: $27^{\circ} 55^{\prime} 60^{\prime \prime} \mathrm{S} 134^{\circ} 45^{\prime} 0^{\prime \prime} \mathrm{E}$.
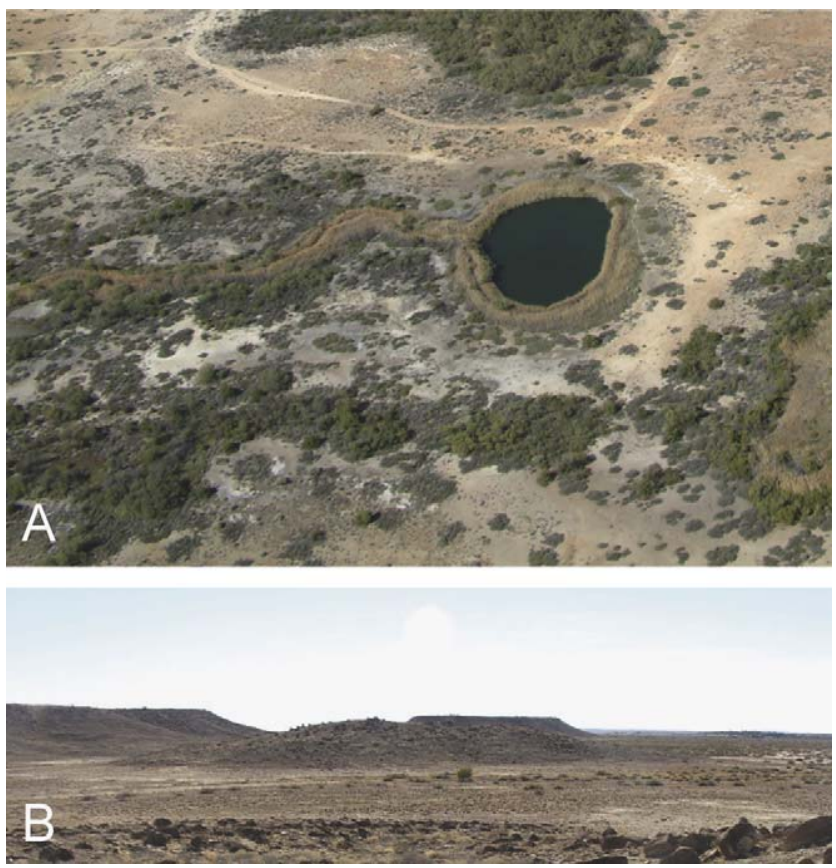

Fig. 5. An aerial view of a spring pool (A) with a sinuous, vegetation-rimmed discharge channel and a small mesa (B) formed by the erosion of a former pool leaving behind a carbonate cap in the Dalhousie Springs exploration zone: $26^{\circ} 25^{\prime} 20.9^{\prime \prime} \mathrm{S} 135^{\circ} 30^{\prime} 11.1^{\prime \prime} \mathrm{E}$

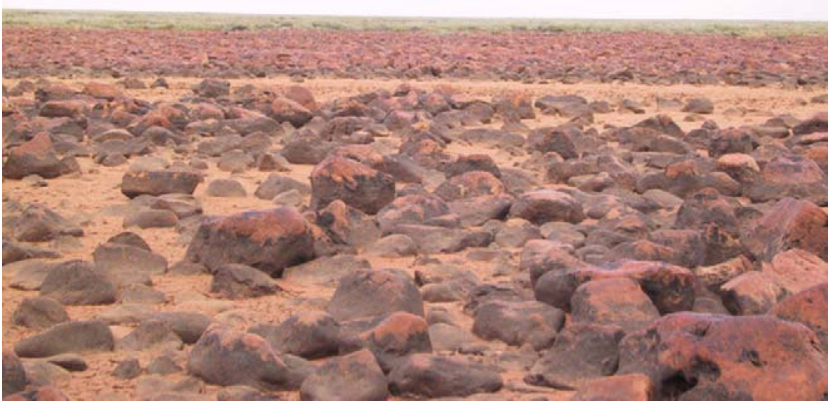

Fig. 6. The gibber plains of the Sturt Stony Desert exploration zone which Thomas et al. (2005) has proposed as an analogue of deflation surfaces imaged at Chryse Planitia by the Viking 1 lander: $28^{\circ} 20^{\prime} \mathrm{S} 138^{\circ} 40^{\prime} \mathrm{E}$.

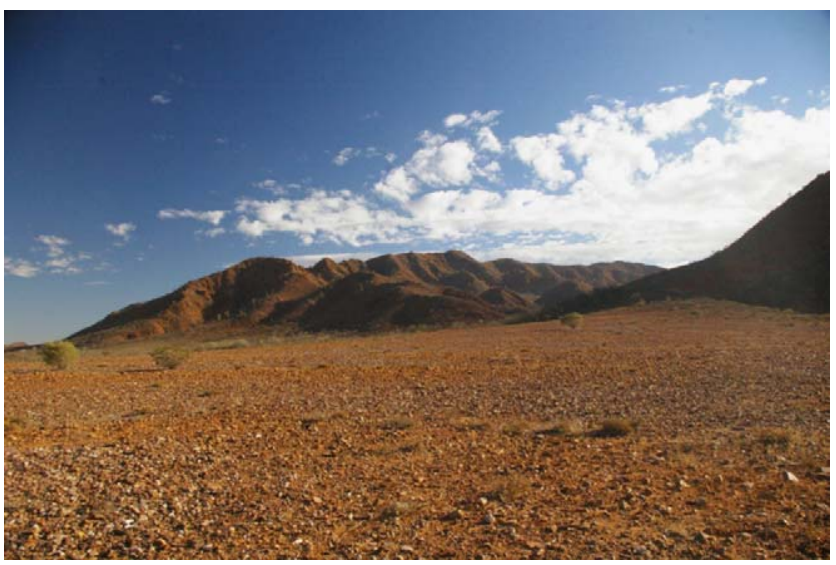

Fig. 7. The proposed site for MARS-Oz in the Arkaroola Mars Analogue Region with the foothills of the Northern Flinders Ranges in the background: $30^{\circ} 18^{\prime} \mathrm{S} 139^{\circ} 20^{\prime} \mathrm{E}$.

iron bearing rocks of the area also act as a visual analogue. The region has good air and road access and is a particularly good location for testing technologies and strategies for the detection of past life on Mars.

\section{Mars analogue spacesuit trials}

The future exploration and settlement of the Moon and Mars will require sustained planetary surface activity and hundreds of extra-vehicular activities (EVAs) by the crew. This will place unprecedented demands on spacesuit systems (Callaway, 1994; Newman and Barrat, 1997; Gernhardt, 2007). EVA history has demonstrated that current gas-pressurized suits are rigid and unyielding when used in the vacuum of space (Harris, 2001; Waldie, 2005). The gloves are a particular hindrance, as all tasks require some form of fine hand functionality. Finger and hand dexterity, strength and endurance are all significantly impacted because of the force required to bend the rigid, gas-pressurized materials from their neutral position (Sorenson et al., 1997; Eckart, 1996; Harris, 2001). Several studies have found that hand grip strength is reduced by $50 \%$, dexterity is reduced by $80 \%$ and perceived comfort is reduced by 600\% (O'Hara et al., 1998; Bishu et al., 1993a, b). Peg board tests have shown that the Phase IV Space Shuttle gloves increase task time to 5-6 times longer than 


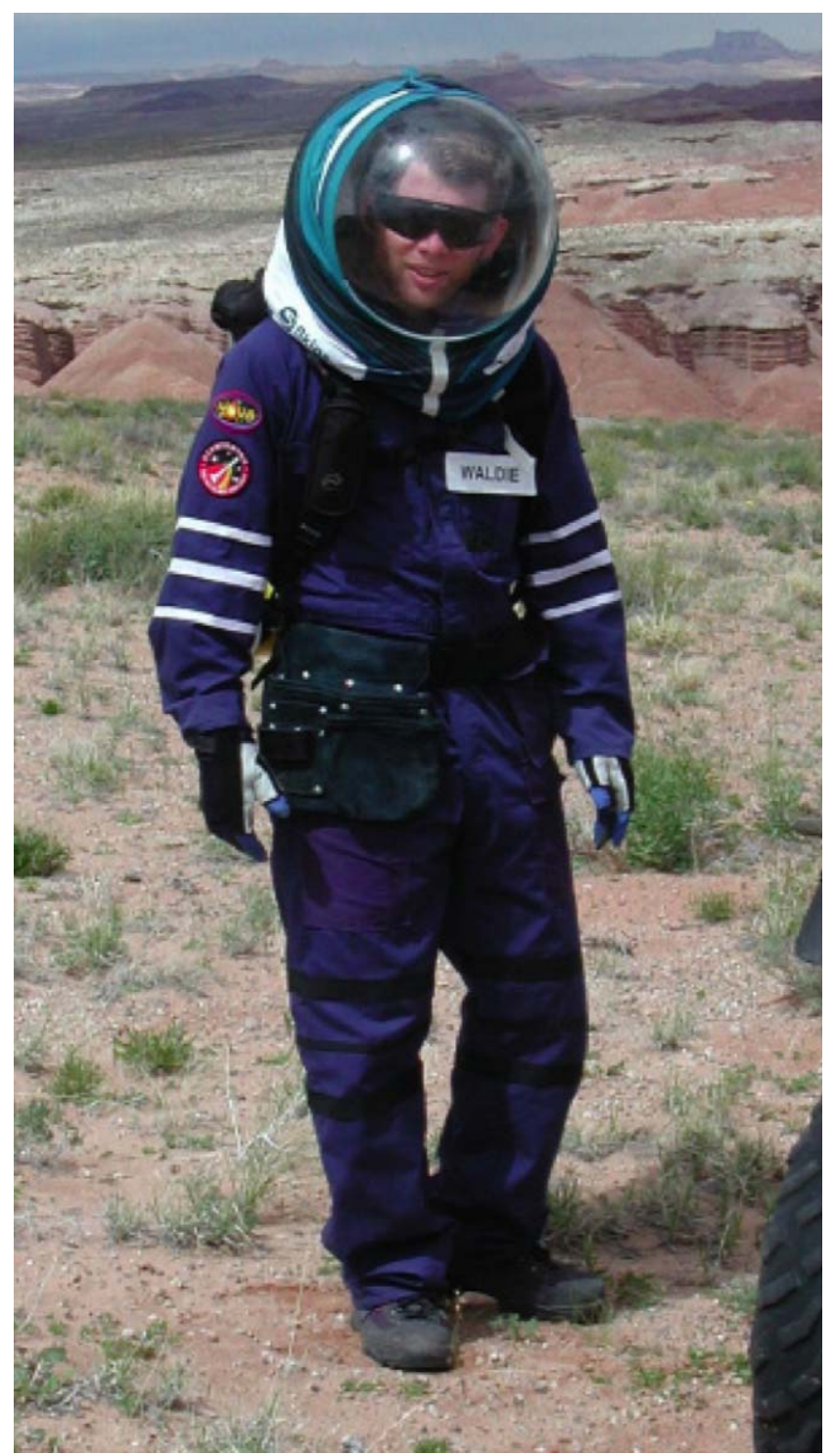

Fig. 8. A front view of the MarsSkin analogue space suit showing the helmet assembly, the outer protective layer and the utility belt.

with the naked hand (Bishu et al., 1993b). Furthermore, the Space Shuttle gloves are often uncomfortable to the point of pain and/or physical injury to the hand (such as fingernail delamination) (Welsh and Akin, 2001; Strauss et al., 2005).

NASA and other agencies agree that innovative spacesuit development is therefore essential to meet current and future EVA demands, since the evolution of gas-pressurization seems unlikely to significantly improve EVA suit effectiveness to the levels required (Herbert, 1993; Newman, 2000; Waldie, 2005). In particular, an improvement to the suit gloves will be critical to successful EVA performance (Cadogan et al., 1993; Graziosi et al., 2001; Jones and Schmitt, 1992; Shepherd and Lednicky, 1990; Scheuring et al., 2007). An alternative approach to EVA spacesuit and glove design uses form-fitting garments to physically compress regions of the body with elastics, instead of pressurization with a gas. The compression of the elastics would be the same as the pressure of the breathing gas in the helmet and so a uniform loading is produced over the entire body (Tanaka et al., 2002; Waldie et al., 2002). This 'skinsuit' approach is called Mechanical Counter Pressure (MCP) and potentially produces a

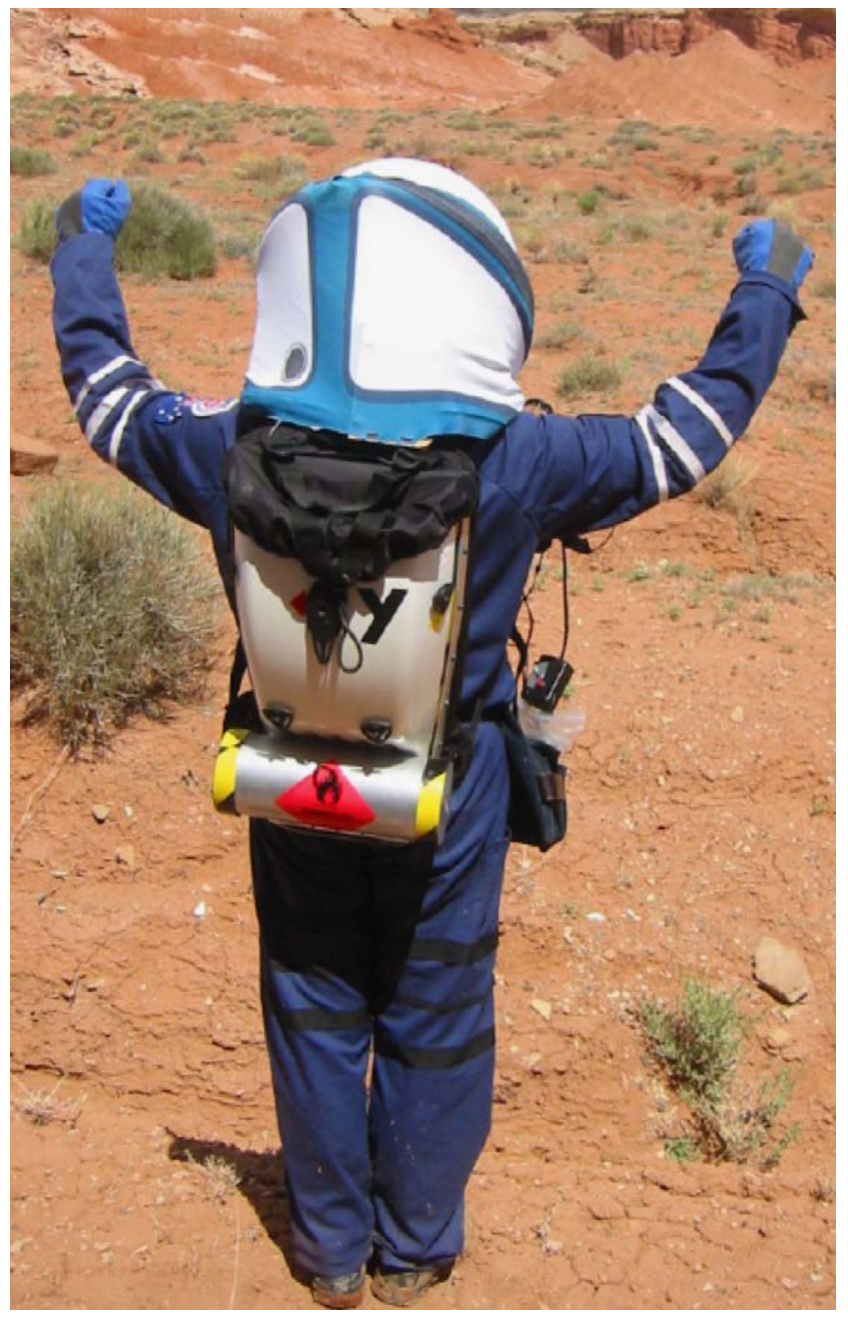

Fig. 9. A back view of the MarsSkin analogue space suit showing the rigid external life support backpack.

light, flexible, cheap and safe compression garment (Annis and Webb, 1971; Clapp, 1984; Annis and Webb, 1967; Waldie, 2005). Previous performance studies with a simple MCP glove found task times to be only 1.37 times slower than barehanded (Clapp, 1984). While MCP has substantial advantages over gas-pressurization, it is not currently a viable life support technology due to donning/ doffing difficulties. However, new research into active elastics may soon produce more feasible designs.

MSA has developed simulation MCP suits based on recent NASA/Honeywell prototypes and full suit theories and concepts. The suits are called MarsSkins and are shown in Figs. 8-10. They are designed to explore the advantages and disadvantages of the MCP approach compared to gas-pressurization. While various studies have been performed using the MarsSkin suits (Waldie et al., 2002; Waldie and Cutler, 2006), the majority of investigations to date have aimed to quantify and compare the performance degradation of the hand due to MCP and gaspressurized gloves.

The construction of the MarsSkin suits is as follows: The helmet is a traditional bubble type, as required for normal breathing, and is fitted with a ventilation system, drink bottle bite valve (with drink bladder in the backpack) and a VOX radio earplug. The backpacks feature a rigid external shell for protection of the life support system internals (Fig. 9). The volume of the pack is approximately equal to that of a real MCP 


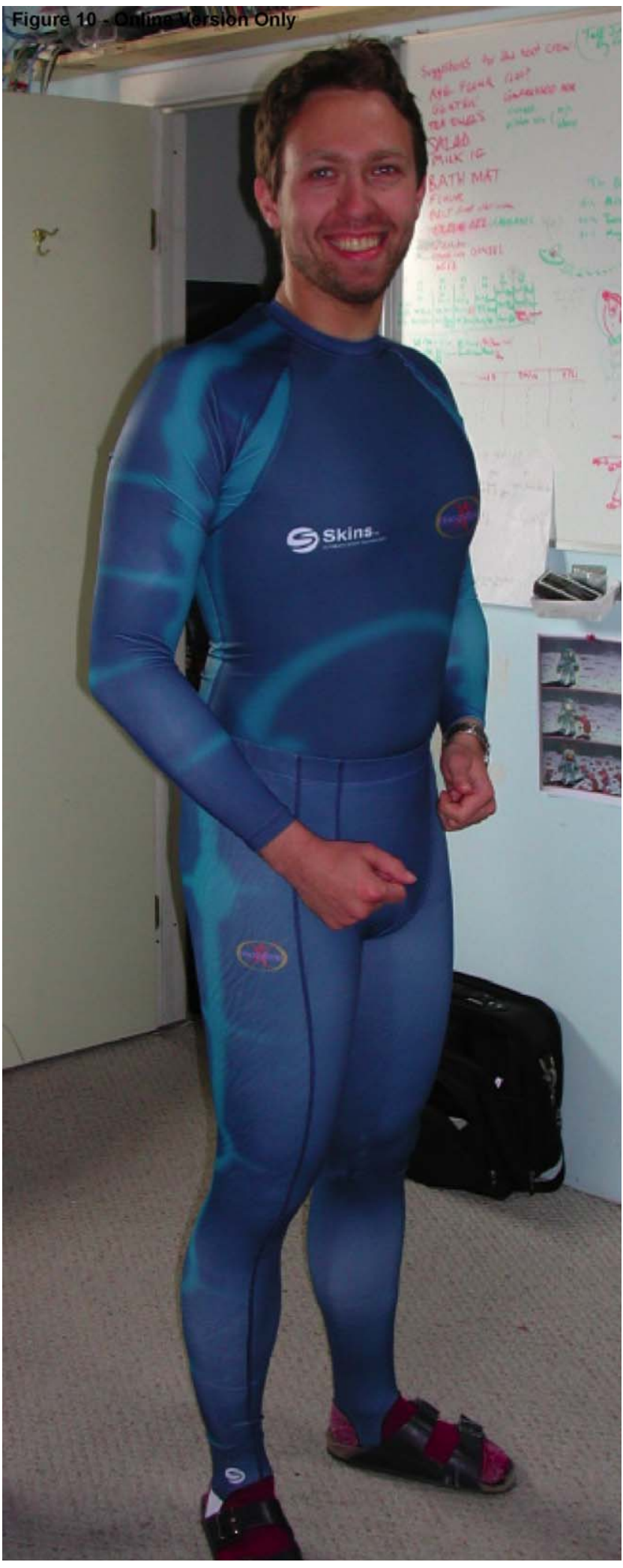

Fig. 10. The analogue MCP layer of the MarsSkin analogue space suit, which is made from a poly-lycra coolmax material with sublimation printing and simulates the compression of a real MCP garment.

suit, and represents a significant reduction in bulk and weight over gas-pressurized backpacks. The most critical improvement, however, is the analogue MCP layer, made of a poly-lycra coolmax material with sublimation printing, and wick perspiration and heat, shown in Fig. 10. This layer simulates the compression of a real MCP garment in the low pressure environment of Mars. The outer protective layer is a heavyweight cotton drill coverall. The MCP analogue gloves are a $60 \%$ polyester/30\% nylon/ $10 \%$ Lycra spandex thermal underlayer glove, which has been shown to most closely represent the performance of prototype Honeywell MCP gloves. A non-stretch synthetic glove with pleated joints was used as the outer protection layer. The gaspressurized glove analogue used is a standard ski glove treated with fabric stiffener, such as that used on the analogue suits used previously at the Mars Desert Research Station (MDRS) in Utah, USA.

\subsection{Jarntimarra trials}

Field trials of prototype MCP gloves were conducted during MSA's Jarntimarra expedition in late 2001 (Mann et al., 2004a). The gloves were worn by several expeditioners while they handled tools such as geo-picks, small spades, shovels and pens during the course of their work. Subjects found that the glove presented only a minor hindrance for tasks requiring significant finger movement, with one subject even happy to eat dinner with the glove on. The MCP glove did not cause tension or fatigue in the finger webbing or hand musculature, and no subjects noted any skin irritation. Subjects noted a slight waffling impression on the skin surface after the glove was removed, which was a result of the elastic weave. This impression remained for several minutes, but was not painful or irritating.

\subsection{Expedition One trials}

In order to quantitatively study glove performance, a range of repeatable EVA tasks can be simulated and the completion time when wearing the MCP and gas-pressurized gloves can be compared to the naked hand. This was first performed during Expedition One at MDRS in Utah in February/March 2003 (Persaud et al., 2004). The MDRS suit gloves were used to simulate gas-pressurization and MarsSkin analogue MCP gloves were also tested against NASA/Honeywell prototypes. Five major factors have been identified as affecting hand and glove performance, ranging from task protocol to glove configuration (O'Hara et al., 1998). For accuracy, this study attempted to keep all contributing factors constant except glove characteristics, so that any change in performance was only due to the glove being tested. Four tests were chosen as broadly representative of future planetary EVA tasks: screwing nuts and bolts (engineering), rock sampling and storing (geology), soil sampling (biology) and typing (suit interface). Seven subjects completed the tests, with results shown in Table 1. The MarsSkin MCP gloves proved to be an accurate analogue of the NASA/Honeywell MCP gloves, since the average difference in task time between the two glove types for the four tests was only $4.7 \%$. On average, the task time with the analogue MCP and the analogue gas gloves was 1.60 and 2.65 times longer than the naked hand, respectively.

\subsection{Expedition Two trials}

Expedition Two was held in the AMAR in South Australia in August 2004 (Clarke et al., 2006a), and allowed significantly more subjects to complete EVA task comparisons than the Expedition One trials. Tasks for this study included screwing nuts and bolts (engineering), rock sampling (geology) and using a Brunton (a common geologic field instrument). Thirty subjects completed the engineering test, 19 completed the Brunton test and 20 completed the geology test. As a larger 
Table 1

Expedition One space suit glove trials.

\begin{tabular}{lllll}
\hline Task & $\begin{array}{l}\text { Naked } \\
\text { hand }\end{array}$ & $\begin{array}{l}\text { NASA/Honeywell } \\
\text { MCP }\end{array}$ & $\begin{array}{l}\text { MCP } \\
\text { analogue }\end{array}$ & $\begin{array}{l}\text { Gas } \\
\text { analogue }\end{array}$ \\
\hline $\begin{array}{l}\text { Engineering } \\
\text { Geology }\end{array}$ & $100 \pm 0$ & $151.3 \pm 12.8$ & $152.2 \pm 10.1$ & $221.2 \pm 22.0$ \\
Biology & $100 \pm 0$ & $256.1 \pm 27.1$ & $230.2 \pm 18.4$ & $499.3 \pm 48.9$ \\
Typing & $100 \pm 0$ & $141.7 \pm 8.0$ & $114.1 \pm 7.2$ & $157.1 \pm 8.5$ \\
\hline
\end{tabular}

Results are shown as \% increase in task time \pm standard error.

Table 2

Expedition Two space suit glove trials.

\begin{tabular}{llll}
\hline Task & Naked hand & MCP analogue & Gas analogue \\
\hline Engineering & $100 \pm 0$ & $148.5 \pm 7.4$ & $248.6 \pm 11.8$ \\
Geology & $100 \pm 0$ & $181.6 \pm 9.5$ & $254.6 \pm 13.2$ \\
Brunton & $100 \pm 0$ & $142.9 \pm 5.6$ & $423.1 \pm 82.5$ \\
\hline
\end{tabular}

Results are shown as \% increase in task time \pm standard error.

number of subjects were tested, a timer and an observer were required to oversee each task. Full results are shown in Table 2. On average, compared to the naked hand baseline, the MCP gloves took 1.58 times longer and the gas gloves 3.09 times longer.

In addition to these three trial campaigns, a comparative study between a MarsSkin suit and an analogue gas pressurized suit was completed by two crews at MDRS. These tests were part of Crews 39 and 40 and were undertaken in April and May 2005.

\subsection{Discussion}

The final results of the comparative tests show that the mean time increase for MCP gloves was 1.65 and 2.84 for gas-pressurized gloves. The figure for gas gloves is considerably smaller than other literature findings and suggests that analogue gas gloves do not fully replicate the true hindrance to glove performance. However, the MarsSkin gloves were shown to be accurate representations of the prototype NASA/Honeywell MCP gloves. This study indicates that MCP gloves may allow astronauts to perform hand tasks up to 4 times faster than with gas-pressurized gloves. This is a significant improvement in EVA hand performance and could enable more productive and capable EVA, while reducing risk, fatigue and error. The benefits to glove performance (and therefore EVA effectiveness) warrant further development of MCP technology and, where possible, will be investigated in Mars analogue conditions.

\section{Field science and instrumentation testing}

\subsection{Remote sensing techniques}

For the purpose of analogue studies, there are many remote sensing techniques that can, and are being used to study and map Mars geology. Testing these methods on analogues on Earth allows protocols to be developed that can be applied to future

\footnotetext{
${ }^{1}$ More information can be found at http://desert.marssociety.org/MDRS/fs04.
}

robotic or manned Mars missions. Previous analogue studies in Australia include the application of spectral remote sensing techniques and hyperspectral methods to map the geology and characteristics of hydrothermal systems (Thomas and Walter, 2002; Thomas et al., 2002). Hydrothermal systems are of particular interest as such sites on Mars may nurture biological activity (Brown et al., 2005). They could also host regions of modern or ancient mineralization, such as that recently postulated by West and Clarke (2010), that could be utilized in future martian settlement activities. Hydrothermal systems can be detected and mapped using spectroscopy since their weathering products are spectrally distinctive.

The hydrothermal systems at Mount Painter in the AMAR and at North Pole Dome in the Pilbara have been of particular interest to the Mars analogue research community in Australia. Hyperspectral data obtained by the airborne HyMap of these locations have been ground truthed using the Australian-built Portable Infrared Mineral Analyzer (PIMA) and a hand-held Short Wave Infra Red (SWIR at $1.3-2.5 \mu \mathrm{m}$ ) analyzer (Brown et al., 2004a, b; Storrie-Lombardi et al., 2004). These datasets have been augmented with satellite derived LandSAT and ASTER data. The PIMA is a SWIR spectrometer with over 600 contiguous spectral bands in the $1.3-2.5 \mu \mathrm{m}$ wavelength range that produces laboratory-quality spectra with a $2 \mathrm{~nm}$ sampling interval and a $<10 \mathrm{~nm}$ resolution. This is particularly useful in classifying and mapping hydrothermal alteration in ancient and active systems, as it enables identification of very small absorption features that can provide detailed crystallographic information, such as the degree of crystallinity and significant mineralogical-chemical variations.

Using this hyperspectral imaging technology, accurate maps of surface mineralogy have been made of both Mt Painter and North Pole Dome. These maps show boundaries, relative abundances and mineral assemblages that enable individual species of iron and clay minerals to be identified. These data provide detailed information about the nature of the hydrothermal mineralization and the relevant alteration zones. This work has demonstrated that future VNIR-SWIR hyperspectral surveys of the martian surface with a spatial resolution approaching $5 \mathrm{~m}$ are sufficient to detect minerals indicative of hydrothermal alteration products. Furthermore, mapping ancient hydrothermal systems with hyperspectral imaging techniques has been shown to be an effective approach that can map minor spectral features in alteration assemblages and identify structures that would be difficult to locate using other techniques (Thomas and Walter, 2002). Current technology is already at a level where air- or satellite-gathered hyperspectral measurements of Mars could produce similar levels of detail about surface mineralogy as is currently done for Earth. Work is ongoing to adapt these techniques to hyperspectral datasets currently being acquired at Mars by the OMEGA and CRISM instruments (Ehlmann et al., 2008).

In addition to the studies above, a hyperspectral survey of the Yilgarn Craton in Western Australia has been carried out using the airborne HyMap instrument and supplemented by ASTER imagery (Brown and Cudahy, 2006). This area is of interest since large deposits of gypsum were detected remotely in the evaporite deposits of the dry lakes that criss-cross the region. These results have been compared to measurements made by the OMEGA instrument of sulfate deposits in the martian North Pole region. Since the ultramafic-mafic volcanic flows of the Yilgarn Craton are a good analogue for the volcanic flood basalts of Mars, detection of sulfate deposits against this backdrop is important to understand the most likely minerals that would be found in a basaltic acid weathered region. This work by Brown and Cudahy (2006) has demonstrated a technique for detecting sulfate deposits on Mars with orbiting instruments. 


\subsection{Testing flight hardware}

Recently, Canadian researchers from York University and Optech Inc. used an Australian desert to test a lidar system analogous to that which flew aboard the Mars Phoenix Lander (Dickinson et al., 2008). During its mission the Phoenix lidar provided spatial and temporal data on the distribution of aeolian scatterers in the martian atmosphere. With the aid of simultaneous measurements with airborne systems, the analogous system indicated that signal enhancements observed on Mars correlated with increased relative humidity in the Australian desert region. This enabled Dickinson et al. (2008) to draw conclusions regarding the vertical water content in the martian atmosphere and further demonstrates the opportunities that Australia's analogue locations offer for testing and calibrating spacecraft instrumentation.

A suitable site at North Pole Dome in the Pilbara region has also been proposed as a possible Mars analogue suitable for testing the European Space Agency's ExoMars rover (Brown et al., 2004). The geological characteristics of the Pilbara region that are of relevance to Mars analogue research have been summarized above and elsewhere in West et al. (2010) in this issue. The site proposed by Brown et al. (2004) has suitable ground cover and slope to challenge a robotic rover and minimal vegetation cover. The rocks are abundant in Fe-oxides, providing visual realism, and could be used to test a rover's panchromatic cameras. The region also has good air and road access and has been extensively studied previously and imaged with various remote sensing instruments, as outlined above. All these characteristics make this location an ideal proving ground for testing technologies and strategies to find past life on Mars in particular. Several locations in the AMAR could also be used to test flight hardware such as the ExoMars rover. Further work is required to evaluate these possibilities.

\section{Human factors research}

Australian activities in the human factors arena have focussed on the productive combination of psychology and industrial engineering methods to investigate Mars analogue and real Mars mission issues regarding the crew, its composition, environment and activities (Dawson et al., 2004). More broadly, human factors research is also concerned with issues such as the impact of microgravity on human biological systems, design of living quarters and group interaction in confined spaces. During Expedition One at MDRS in 2003, a variety of objective and subjective means were used to collect data amongst the crew as they participated in a 30-day medium-fidelity Mars surface simulation mission. Objective data were collected using social psychological questionnaires, computer based neurocognitive testing, a battery of personality tests, job analysis, work measurement and ergonomic data collection, workload assessment and time lapse video recording. For example, the cognitive performance data were gathered by Osburg et al. (2003) using software originally developed-and currently being used-for evaluating the cognitive performance of astronauts on board the International Space Station. The experiment provided insights into the variation of the test subjects' cognitive performance over time, while they were affected by a variety of stressors caused by simulated exploration mission activities, station systems operation and group interaction. Subjective data were obtained via observations of and discussions with crew members by the expedition's human factors officer and the use of diaries and reports of mission activities.

Building upon these experiences and the techniques used during Expedition One, the human factors research during
Expedition Two in the AMAR investigated the impact of group and sub-group identity and goal alignment on motivation, effort to achieve group goals, and effective communication both within a particular group and between subgroups (including 'mission control'). A number of personal well-being measures were included, for example stress, and mental health, along with measures that attempted to assess which self-categorizations are utilized by individuals in the course of a day. Other issues investigated included group polarization and ostracism. A considerable volume of data, in the form of questionnaires, computerbased measurements of cognitive function, and observations by the expedition psychologist, were generated during the course of the expedition. Preliminary results are being analysed and will assist with the development of human factors research programs for future activities.

In addition to activities in the Mars analogue localities on the Australian continent, Australia has been involved in research in Antarctica that is relevant to space and Mars exploration. Antarctica is a hostile, dangerous and unfamiliar environment and despite modern technology, its total physical isolation, cold and marked photoperiodicity, make it one of the most extreme and isolated places on Earth and therefore an outstanding analogue for the isolation and confinement of space missions (Lugg, 1994; Suedfeld and Weiss, 2000; Suedfeld, 2010). The small, confined groups that winter over in Antarctica are dependent upon technology for their survival in much the same way that astronauts undertaking expeditions to Mars would be dependent on advanced technology for food, shelter, environmental control, communications and general survival.

The Australian Antarctic Division (AAD) via its Australian National Antarctic Research Expeditions (ANARE) has been carrying out medical research on groups staying at Mawson, Casey, Davis stations and on the sub-Antarctic Macquarie Island for over 50 years (Lugg and Shepanek, 1999). A collaboration that began in the early 1990s with NASA's Life Sciences Division has undertaken research into immunology (Shearer et al., 2001; Tingate et al., 1997), microbiology (Shearer et al., 2002), psychology (Wood et al., 2005; Schmidt et al., 2005) and remote medicine and has produced important insights into how humans adapt to the stress of extreme isolation, confinement and the harsh environment of Antarctica. Just like astronauts undertaking space missions, ANARE participants support peer reviewed scientific research: in biology, geology and meteorology for example. These expeditions therefore provide an excellent analogue for the task orientation (scientific research) and the work environment that groups in space experience. In one such study, Wood et al. (1999) investigated psychological changes, using computer-administered questionnaires, in two Australian teams undertaking 100-day traverses around the Lambert Glacier Basin and found only small trends. Lugg (2005) also concludes that, based on evidence from Antarctic studies, the likelihood of behavioural health issues in space is low. However, it is noted that if they occur such cases may be serious and of high consequence. Such events would place considerable demands upon mission crews and ground support to achieve favourable outcomes, given the limited resources available.

In addition to the analogue value to astrobiologists of Antarctica's dry valleys and perennially frozen lakes (Andersen et al., 1992; Doran et al., 1998; Gilichinsky et al., 2007), numerous opportunities exist for further human factors research relevant to Mars exploration in Antarctica. Research could be undertaken as part of the AAD's future expeditions or via participation in the activities of other countries, such as at the French Concordia station (Godon et al., 2007; Tafforin, 2005). It is hoped that such opportunities will be pursed by researchers in the future. 


\section{Analogue crewed surface vehicles for exploration}

\subsection{Project Marsupial}

Project Marsupial is a long term research and development effort to decide on the requirements, design and operational procedures for a crewed, pressurized, long-range surface exploration vehicle for Mars exploration (Mann, 2006). Such a vehicle would be capable of carrying up to four persons away from the base camp at a Mars landing site for days to weeks at a time. The main deliverables of the project are the Starchaser Rover, a working prototype vehicle, together with development notes and performance data recorded during a series of simulated test operations in Australian Mars analogue regions. The aim is to begin a practical iterative development effort and explore design options that add to the body of knowledge drawn upon when developing actual flight hardware.

The prototype surface vehicle will help answer questions such as:

- What is the optimal crew size for vehicle exploration?

- What equipment is needed for successful exploration work?

- What are the optimal exploration strategies that must be adopted for safe operation of a crewed vehicle?

- How far from a Mars habitat can a crewed vehicle safely travel?

- Does the vehicle need to be completely pressurized?

As a medium-fidelity prototype that must be practically and legally driveable on Australian roads, the Starchaser Rover cannot address certain technical issues, such as a true cabin pressurization, power plant, transmission and man-rated life support equipment design. Instead, the analogue vehicle strives to approximate the living and working facilities required for long duration excursions into the Martian environment. The Starchaser Rover is presently under construction in Western Australia (Fig. 11) and is principally funded by Starchaser Industries, a UK aerospace company.

\subsection{Studies of real and envisaged crewed surface vehicles}

The construction of the Starchaser Rover has been slow due to limitations of available labour (Mann, 2004). While awaiting delivery, however, MSA has continued the project by conducting a practical field comparison of three low-fidelity pressurized crewed vehicle designs under realistic simulation conditions (Mann et al., 2004b, c) and a 'forward engineering' study of hypothetical crewed vehicle operations and requirements (Clarke et al., 2008) within the constraints of the mission architecture discussed in Section 7.

The conceptual designs, interior layouts and operational performances of three pressurized crewed vehicle prototypes were field tested during Expedition One at MDRS in Utah (Persaud et al., 2004). This was a human factors experiment, in which the same crew of three executed the same simulated science mission in each of the three vehicles shown in Fig. 12-the Everest Rover (Paulson et al., 2004), the ARES Rover and a Sports Utility Vehicle (SUV). This study yielded comparative data on the capacity of each vehicle to safely and comfortably carry explorers away from the main habitat, enter and exit the vehicle in spacesuits, perform science tasks in the field and manage geological and biological samples. As well as offering recommendations for design improvements for specific vehicles, the results indicated that a vehicle the size and layout of a SUV would be inadequate and that a pressurized docking tunnel to the main habitat is essential. Special provisions for spacesuit storage and recharging were

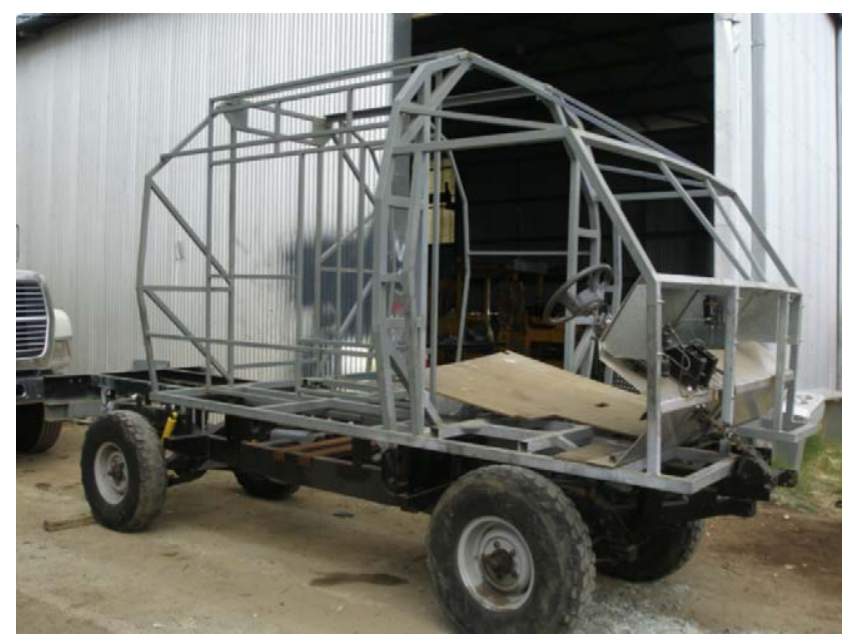

Fig. 11. The frame and chassis of the Starchaser Rover under construction.

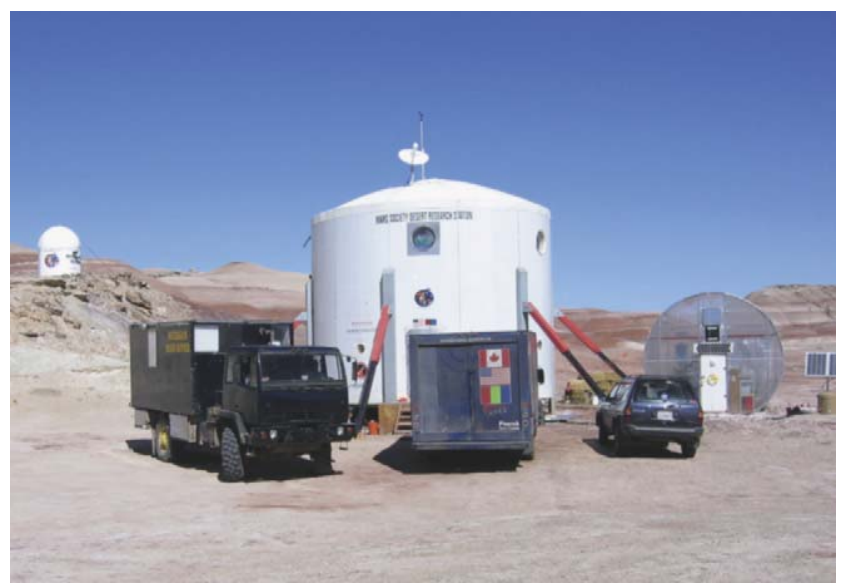

Fig. 12. Three low-fidelity pressurized surface vehicle prototypes under test at the Mars Desert Research Station in Utah during Expedition One (Persaud et al., 2004). From left to right are the Everest Rover, the ARES Rover and the Sports Utility Vehicle (SUV) used.

found to be crucial and it was also determined that a crew consisting of one driver/navigator and two field science crew specialists may be optimal (Mann, 2004).

These incidents also further highlighted the need for a pressurized docking tunnel. An analysis of these incidents led to proposed refinements of operational protocols and specific crew training for rover returns. They also again pointed to the need for a pressurized docking tunnel. Sound field testing, circulation of results and incorporating the lessons learned into new vehicle designs were advocated as a way of producing higher fidelity crewed vehicle analogues in the future.

The recently completed 'forward engineering' study by Clarke et al. (2008) aimed to apply what had been learned to date while designing and building the Starchaser Rover in order to reveal new perspectives on crewed Mars vehicles and to better conceptualize final flight hardware. The mission architecture discussed in Section 7 provides for four surface vehicles, with an overall mass budget of 5 tonnes. These vehicles would include:

- One 3-3.5-tonne pressurized vehicle (similar to the Starchaser Rover). 
- Two 0.5-tonne unpressurized vehicles for short range transport and earth moving.

- One 0.5-tonne robot vehicle with specialized attachments that is capable of assembly and maintenance tasks, for example laying down and cleaning a solar cell carpet to supply power for the ISRU plant.

These vehicles and the science aims of the mission architecture were examined with a particular emphasis placed upon maximizing crew safety, the vehicle system requirements, the technological capability to deliver the mission requirements and design and operations issues arising for study in the future. The process of maximizing crew safety began by analysing general modes of failure and travel range safety of the pressurized vehicle. Possible modes of failure for the pressurized vehicle were found to include general vehicle system failures, such as failures of wheels, drives, loss of propellant, cabin environment, vehicle structure, navigation and communication equipment; travelling accidents including collisions and the vehicle rolling or becoming bogged; and solar storms irradiating the crew.

This analysis and a review of other planetary vehicle, such as the Soviet Lunakhod and NASA's MER robots (and more recently the ATHLETE and CHARIOT rovers), led to new design requirements being identified for future flight hardware. This led to the following conclusions:

- the range of the pressurized vehicle should be 10 sols' travel with two passengers or in an emergency five sols' travel with four passengers;

- the range of the unpressurized vehicle should be one sols' travel, since the crew should not travel at night;

- the pressurized vehicle could take the form of a utility truck carrying a detachable, self-contained cabin module (a design concept of the Starchaser Rover);

- the vehicles should draw upon 60 years of ordinary off-road vehicle design and employ four or six wheels with a simple chassis design;

- all vehicles should be able to be operated autonomously or semi-autonomously without a crew. They must be able to be remotely teleoperated from the safety of the Mars habitat if required;

- the vehicles will be electrically driven from a $\mathrm{CO} / \mathrm{CO}_{2}$ fuel cell or batteries via an electronic transmission to a separate motor in each wheel; and

- all the unpressurized vehicles will share a 'core design' with detachable robot arms, blades, scoops and crane for minor civil and construction work. This is to provide maximum flexibility and redundancy for those operating the vehicles.

Finally, technical and design issues were identified for future investigation. These included the method by which the crew enter and egress the pressurized vehicle and the crew's transfer to and from the Mars habitat and the safety and reliability under semi-automated control of vehicle tool reconfiguring, refuelling and other operational tasks. Future research should also demonstrate safe vehicle operation with all systems integrated, investigate airlock designs, evaluate field maintenance of space suits and the effectiveness of multi-purpose vehicle design. These issues will be actively pursued during field trials of the Starchaser Rover in the Mars analogue locations of central Australia in the future.

\section{Mission architecture studies}

In support of the MARS-Oz project, a theoretical study has been undertaken to develop a Mars mission architecture for a real Mars expedition that utilizes a horizontally landed bent biconic vehicle. The study developed a 'family' of concept vehicles engineered to a level that could provide shapes and masses suitable to plan the infrastructure for manned Mars missions (Willson et al., 2005; Willson and Clarke, 2005). The resulting mission architecture (Willson and Clarke, 2006) is similar to that outlined by Zubrin and Baker (1992) and the NASA 'Design Reference Mission' architecture (Duke and Budden, 1993), yet with some significant differences.

Initially, the study began by assessing the problem of travelling to and living on Mars from the perspective of an explorer standing on Mars, asking the following questions:

- What equipment do I need to explore Mars?

- What structures are easiest for me to live and work in?

- What equipment do I need to live on Mars for long periods?

This approach differs from that used by other Mars mission architecture designers, who generally view the problem in terms of converting a space vehicle into a Mars base. Willson and Clarke (2005) concluded that given the high cost of transporting infrastructure to Mars, which has an expected life of 25-50 years, a better strategy is to design structures that are efficient and practical as 'houses for living and working on Mars, rather than just efficient spacecraft with the design focused on travelling to and from Mars.' Therefore, it was concluded that Mars explorers would need pressurized and unpressurized rovers for exploration, solar power generators, a habitat, food, air and supplies, science equipment and vehicles for the extraction of hydrated soil for future water supplies (Clarke et al., 2006b).

This led to the selection of a $21 \mathrm{~m}$ long, 62 tonne horizontally landed bent biconic vehicle as the centrepiece of building a Mars base and transporting infrastructure to Mars. The size and mass chosen provides a cargo and habitation module for a minimum of four person crew with a $20 \%$ margin. A horizontally landed bent biconic vehicle was chosen as it has many advantages over blunt end vehicles common in other Mars mission architectures. These include a better lift/drag ratio for entry into the martian atmosphere than traditional blunt end vehicles and a low deceleration $g$ loading, which both provide greater manoeuvrerability for more accurate landing on Mars, a superior cargo carrying capacity, easier loading, unloading and entry and egress and a configuration which offers growth potential by simply lengthening the module. The low shape makes it easier to cover the vehicle with regolith for radiation protection and, with the addition of wheels, towing and repositioning on the surface of Mars can be facilitated. The propellant tanks and propulsion unit can also be removed from the tail after landing, leaving a useful safe structure for long term habitation.

There are, however, several disadvantages with a horizontally bent biconic vehicle design. These include the need for a more complex and heavier four engine auto-throttling system for landing than the minimum one engine system needed on a tail landed vehicle. Horizontally landed bent biconic vehicles also do not have a re-entry vehicle 'history' like cone shaped vehicles. Some investigations into this issue have been undertaken but more studies are required.

Following the selection of the vehicle type and size, Willson and Clarke (2005) developed a Mars mission architecture for a 
'first' Mars mission using the proposed vehicle. A number of basic assumptions were made. These included:

- nuclear power for electrical generation would be excluded due to the political issues associated with launching nuclear material;

- In-situ Resource Utilization (ISRU) would be adopted to make propellant for the return journey and to produce oxygen and water for the crew. The ISRU plant works by manufacturing propellant from $\mathrm{CO}_{2}$ from the martian atmosphere and hydrogen transported to Mars in the cargo vehicle;

- an aerocapture manoeuvre would be employed to achieve Mars orbit;

- the selection of the NASA Ares V launch vehicle as the primary launch vehicle.

In addition, a set of design considerations were adopted by Willson and Clarke (2005). In descending order of priority were: minimum cost, maximum safety, minimum complexity and maximum science return.

Given the above assumptions and priorities, a 'family' of concept vehicles were developed including a 62 tonne horizontally landed bent biconic Habitation vehicle that travels to Mars orbit in advance and later lands with the crew and another 62 tonne Cargo vehicle that travels to the surface Mars. The latter lander carries a robot rover that can erect a solar power generator for the ISRU plant. A 130 tonne Mars transfer vehicle (MTV) ferries the crew to Mars orbit and returns them to Earth and a 18 tonne Mars ascent vehicle (MAV) that fits in the cargo vehicle is used to lift the crew to low Mars orbit. It is fuelled by the ISRU plant included in the Cargo vehicle.

By not adopting nuclear power in this mission architecture, solar cells are needed for power generation. This placed a clear limit on the available electric power due to the large size of solar cells that could be practically erected. The limited power, in turn, limits the quantity of rocket propellant that could be made for the MAV. As a result, the MAV needed to be as small as possible and can only lift the crew and rock samples to low Mars orbit. The MTV vehicle uses the aerobrake process to 'park' in low Mars orbit. Therefore, a jettisonable heatshield and retractable solar panels are required. A supply module, used to store science equipment and supplies en-route to Mars, is jettisoned prior to the earth return burn. A conical entry capsule is used to land the crew on Earth.

In summary, the Mars mission architecture proposed by Willson and Clarke (2005) uses bent biconic vehicles to land a minimum of a four person crew, a pressurized surface exploration vehicle, three unpressurized surface vehicles, a $45 \mathrm{~kW}$ solar power generator for the base, a $30 \mathrm{~kW}$ solar power generator for the ISRU plant and supplies for a 600 day stay on Mars. The total mass required to be lifted to low earth orbit is 700 tonnes, which includes the trans-Mars injection boosters. This could be achieved with four launches by an Ares V class booster.

\section{Education and public outreach}

Mars analogue sites in Australia have proved to be a valuable platform for education and outreach activities aimed at fostering an interest in science and technology and an appreciation of the relevance and importance of space exploration amongst the general public (Clarke et al., 2006a; Laing et al., 2004, 2006; Mann et al., 2004a). Three programs have been of particular importance within the Australian context: Expedition Two, Spaceward Bound and MarsSkin. They all leverage off the unique Mars-like landscapes of central Australia and, in particular, the AMAR. All programs have involved MSA in their planning and execution. Educational and outreach opportunities either form the basis of or have been strategically built into these programs (Laing et al., 2004, 2006). Liaison with the media and exposure through radio, television and newspaper coverage has brought these activities before a wider audience and highlighted some of the visual similarities between Australian Mars analogue sites and the surface of Mars, as well as showcasing the various innovative space-related research being undertaken in Australia.

\subsection{Expedition Two}

During Expedition Two to the AMAR in 2004, groups of students from the International Space University's Summer School Program, held in Adelaide that year, were also hosted. The students attended guest lectures by crew members and were able to observe research conducted in situ. Undergraduates from the University of Technology, Sydney also visited the crew during Expedition Two and studied the geological/biological importance of Arkaroola and its environs (Laing et al., 2006; Clarke et al., 2006a). In addition, seminars were held for visitors to the Arkaroola Resort and crew members attended social events held at the resort such as BBQ evenings. This provided opportunities for the researchers to showcase their work, including the MarsSkin analogue spacesuit. Extensive media exposure of crew activities in national newspapers, radio interviews and television programs during Expedition Two illustrated the benefits of analogue research to the general public.

\subsection{Spaceward bound}

The latest education and outreach initiative at the AMAR is the Spaceward Bound program, originally developed by NASA to develop a connection between science and the education community (Heldmann et al., 2007). A Memorandum of Understanding was signed between MSA and NASA Spaceward Bound in July 2007, paving the way for joint collaboration in this program. Two Australian teachers participated in a Spaceward Bound expedition to the Mojave Desert in March 2008, including the education officer of MSA, and the first Spaceward Bound Australia One (SBA1) expedition took place in July 2008. Participants, mainly teachers, visited the various astronomical and historic launch facilities and areas of geological significant for Mars training here in Australia, including the Woomera rocket range, the AMAR and Wilpena (Rawnsley Park). This trip also served as preparation for a Spaceward Bound program that was hosted by Australia in July 2009. This program involved US and Australian teachers participating under the auspices of NASA's Exploration Systems Mission Directorate (ESMD). The aim of Spaceward Bound Australia 2009 (SBA2009) was to enable teachers to gain experience and knowledge of analogue research and how this can be used to progress our understanding of systems elsewhere on Earth and ultimately on Mars. The program was developed so teachers could incorporate these experiences and knowledge in their classroom and their own curricula development. SBA2009 was a resounding success with 15 scientists and 14 teachers and support crew from across Australia and the US participating in astrobiological field work activities around the AMAR over an 8 day period.

\subsection{MarsSkin}

The analogue MarsSkin space suits have often been featured in the media due to their visual impact and they help to make 
analogue research more 'real' to the public. The MarsSkin team have also built 15 simulated space suits based on the MarsSkin concept for the Victorian Space Science Education Centre (VSSEC) (Spencer et al., 2005). The centrepiece of VSSEC is a large simulated martian environment in which high school students carry out a range of scientific and engineering tasks. The space suits developed by MSA are worn by the students during these activities and engender excitement and a feeling of authenticity, which may translate into greater learning outcomes.

\subsection{Other activities}

Several other activities have been undertaken in Australia to engage the students, educators and the general public in Mars analogue research. Most notable of these is the NASA-Macquarie University Pilbara Education Project developed by the Australian Centre for Astrobiology (ACA) and the Macquarie ICT Innovations Centre in partnership with NASA Learning Technologies (Oliver et al., 2006; Fergusson and Oliver, 2006). This project captured 'science in the making' during a 2005 field trip by an international team to key Mars analogue sites in the Pilbara region of Western Australia. Using tools such as Virtual Field Trip, WorldWind, Virtual Lab and What's the Difference?, the project aims to engage high school students and the broader public in cutting edge science. The Pilbara Project is open source and free ${ }^{2}$ and has attracted 4.5 million hits in its first year. It has been tested extensively with students and teachers in Australia and the UK (Oliver, 2007) and formed part of a broader study of scientific literacy and communicating astrobiology to the public (Oliver, 2008).

The Victorian Space Science Education Centre (VSSEC) is a Victorian Government initiative aimed at giving Australian students an opportunity to experience the excitement of space exploration and inspire them to consider a career in science and technology. VSSEC is equipped with the resources for science teachers to take their class on a simulated geological field trip of Mars (Spencer et al., 2005). Students put on MarsSkin space suits, as discussed above, before stepping out onto the surface of Mars under the direction of their fellow students in a simulated Mission Control. Students then explore the unique simulated martian surface, which is an integral component of VSSEC's Mission to Mars program. This surface makes it possible for students to test the moisture and magnetic properties of Mars and collect geological samples, which they then analyse in the on-site research laboratory at VSSEC.

MSA has also been involved with various curriculum development programs and education activities with schools in Western Australia (Gargano, 2007) and New South Wales; the latter as collaborator on an Australian Schools Innovation in Science, Technology and Mathematics (ASISTM) project. The ASISTM project, entitled Bioastronomy and Contextual Learning in the Middle School' aimed to use the relatively new scientific discipline of bioastronomy to develop a fully integrated science, technology and mathematics unit focussed on a martian rock sample that was examined for past or present life. The project involved secondary and primary school teachers, Teacher Associates from the SETI Institute, MSA, the Macquarie ICT Innovations Centre, ACA and consultants from the University of Western Sydney and NASA. Teachers worked with Teacher Associates and partner organizations to develop the unit. A particularly innovative aspect of the project was the involvement of Year 8 students as peer tutors to engage Year 5 students in the complementary construction and programming of a model robotic martian rover.

\footnotetext{
${ }^{2}$ More information can be found at http://quest.nasa.gov/vft.
}

\section{Summary}

Australia has much to offer researchers interested in testing technologies and strategies for Mars exploration. The unique combination of aridity and ancient terrain has preserved numerous geological features and processes analogous to those found on Mars. A wide range of environments suitable for testing instruments, methodologies and equipment are present and have been focussed around the AMAR in South Australia and the Pilbara Craton in Western Australia. The AMAR, in particular, is a good location for free-ranging Mars analogue mission simulations.

Various technologies have been tested in Australia's Mars analogue locations during several research expeditions over the past few years. These include analogue space suits based upon MCP technology and a number of remote sensing instruments. The Starchaser Rover, an analogue crewed rover vehicle currently being constructed, and other work on crewed surface vehicles will provide further opportunities to enable Mars analogue research focussed on mobile platforms, crew traverses and operations. An Australian developed Mars mission architecture that utilizes a horizontally landed bent biconic vehicle has also been reviewed. Australian human factors research undertaken on expeditions to Mars analogues and during activities in Antarctica have been reviewed and future opportunities discussed. Finally, education and public outreach initiatives in Australia abound, including those that utilize innovative information communications technology to communicate science to the general public.

\section{Acknowledgements}

The authors are grateful to Dr. Desmond Lugg, formerly of the Australian Antarctic Division, for providing background information on research undertaken in Antarctica. The authors wish to thank Mars Society Australia, the Australian Centre for Astrobiology, Starchaser Industries, Arkaroola Resort and Wilderness Sanctuary and the numerous other organizations, institutions and individuals that have supported Mars analogue research in Australia over the past decade.

\section{References}

Allwood, A.C., Walter, M.R., Kamber, B.S., Marshall, C.P., Burch, I.W., 2006 Stromatolite reef from the Early Archaean era of Australia. Nature 441 (7094), 714-718.

Andersen, D., McKay, C., Wharton, R., Rummel, J., 1992. Testing a Mars Science Outpost in the Antarctic Dry Valleys. Advances in Space Research 12 (5), 205-209.

Annis, J., Webb, P., 1967. The Principle of the Space Activity Suit. CR 973, National Aeronautics and Space Administration.

Annis, J., Webb, P., 1971. Development of a Space Activity Suit. CR 1892, National Aeronautics and Space Administration.

Bishu, R.R., Klute, G., Kim, B., 1993a. Investigation of the effects of extra vehicular activity (EVA) gloves on performance. Advances in Industrial Ergonomics and Safety V, 683-690.

Bishu, R.R., Klute, G., Kim, B., 1993b. The effects of extra vehicular activity (EVA) gloves on dexterity and tactility. In: Proceedings of the Human Factors and Ergonomics Society: 37th Annual Meeting: Designing for Diversity, pp. 826-830.

Brown, A., 2004. Mars analogue test site proposal-North Pole Dome, Western Australia. In: Harris, R.A., Ouwehand, L. (Eds.), Proceedings of the 3rd European Workshop on Exo/Astrobiology, vol. 545, pp. 177-178.

Brown, A., Allwood, A., Walter, M.R., van Kranendonk, M., 2004. Martian analogue test site-Pilbara Craton, Western Australia. In: 35th COSPAR Scientific Assembly, COSPAR, vol. 35, Plenary Meeting, p. 4255.

Brown, A., Walter, M., Cudahy, T., 2004a. Short-wave infrared reflectance investigation of sites of paleobiological interest: applications for Mars exploration. Astrobiology 4 (3), 359-376.

Brown, A.J., Cudahy, T.J., 2006. Hyperspectral Imaging of sulfate evaporate deposits in Western Australia and on Mars-art. no. 606201. In: Spectral Imaging: Eighth International Symposium on Multispectral Color Science, vol. 6062, pp. 6201-6201. 
Brown, A.J., Walter, M.R., Cudahy, T.J., 2005. Hyperspectral imaging spectroscopy of a Mars analogue environment at the North Pole Dome, Pilbara Craton, Western Australia. Australian Journal of Earth Sciences 52 (3), 353-364.

Brown, A.J., West, M.D., Thomas, M., 2004b. Remote methods for detection of hydrothermal activity in Mars Analogue regions, an example from the Mt. Painter Inlier, northern Flinders Ranges, South Australia. In: Proceedings of the 4th Australian Mars Exploration Conference. Mars Society Australia, University of South Australia, Adelaide, July-August.

Cadogan, D., Bradley, D., Kosmo, J., 1993. Spacesuit glove manufacturing enhancements through the use of advanced technologies. In: Proceedings of the 23rd International Conference on Environmental Systems. No. SAE Paper 932102. Society of Automotive Engineers, Colorado Springs, CO, July.

Callaway, R., 1994. Advanced EVA systems program plan. Technical Report, National Aeronautics and Space Administration, Washington, DC.

Clapp, W., 1984. Advanced spacesuit glove design. In: McKay, C.P. (Ed.), The Case for Mars II: Proceedings of the Second Case for Mars Conference. Science and Technology Series, vol. 62. American Astronautical Society, July, pp. 469-488.

Clarke, J.D.A., Mann, G.A., Willson, D., 2008. Crewed vehicles for Mars exploration-towards a set of requirements. In: Proceedings of the 8th Australian Mars Exploration Conference. Mars Society Australia, University of South Australia, Adelaide, July.

Clarke, J.D.A., Persaud, R., Rupert, S., Bishop, M., Brown, A., Clarke, A., Clarke, J.P., Clarke, R., Cutler, N., Dawson, S., Fitzsimmons, K., Gostin, V., Heldmann, J., Jordan, S., Karouia, F., Krins, P., Martinez, E., Matic, V., Murphy, G., Rupert, A., Stansfield, N., Tanner, M., Thomas, M., Waclawik, V., Waldie, J., Willson, D., 2006a. A multi-goal Mars analogue expedition (expedition two) to the Arkaroola region, Australia. In: Clarke, J.D.A. (Ed.), Mars Analog Research. Science and Technology Series, vol. 111. American Astronautical Society, San Diego, CA, pp. 3-15.

Clarke, J.D.A., Thomas, M., Norman, M., 2004. The Arkaroola Mars analogue region, South Australia. In: Mackwell, S., Stansbery, E. (Eds.), Lunar and Planetary Institute Conference Abstracts. Lunar and Planetary Institute, vol. 35, Technical Report, March, p. 1029.

Clarke, J.D.A., Willson, D., Cooper, D., 2006b. In-situ resource utilisation through water extraction from hydrated minerals-relevance to Mars missions and an Australian analogue. In: Proceedings of the 6th Australian Mars Exploration Conference. Mars Society Australia, Victorian Space Science Education Centre, Melbourne, July, pp. 1-16.

Dawson, S.J., Roesch, J.E., Solignac, A., 2004. Human factors studies for a Mars expedition. In: Cockell, C.S. (Ed.), Martian Expedition Planning. Science and Technology Series, vol. 107. American Astronautical Society, pp. 403-409, Meeting on Martian Expedition Planning, London, England, February 24, 2003.

Dickinson, C., Whiteway, J., Popovici, V., Komguem, L., Cook, C., Seabrook, J., Carswell, A., Daly, M., Team, P., 2008. Desert dust in the atmospheres of Earth and Mars. In: AGU Fall Meeting Abstracts, December, B1415.

Doran, P., Wharton, R., Des Marais, D., McKay, C., 1998. Antarctic paleolake sediments and the search for extinct life on Mars. Journal of Geophysical Research-Planets 103 (E12), 28481-28493.

Duke, M., Budden, N.A., 1993. Mars Exploration Study Workshop II. CP 3243, National Aeronautics and Space Administration, NASA Ames Research Center, November.

Eckart, P., 1996. Spaceflight Life Support and Biospherics. Kluwer Academic Publishers, Dordrecht.

Ehlmann, B.L., Mustard, J.F., Murchie, S.L., Poulet, F., Bishop, J.L., Brown, A.J., Calvin, W.M., Clark, R.N., Des Marais, D.J., Milliken, R.E., Roach, L.H., Roush, T.L., Swayze, G.A., Wray, J.J., 2008. Orbital identification of carbonate-bearing rocks on Mars. Science 322, 1828-1832.

Fergusson, J., Oliver, C.A., 2006. Learning in authentic Earth and planetary contexts. In: AGU Fall Meeting Abstracts (ED43B-0934), December, C2.

Gargano, M., 2007. Space Science and Education: sparking, signing and securing the space generation. In: Proceedings of the 7th Australian Mars Exploration Conference. Mars Society Australia, Perth, Western Australia, July, pp. 1-7.

Gernhardt, M., 2007. Pressurized rover and eva concepts-exploration systems mission directorate lunar architecture update. In: AIAA Space 2007 Conference \& Exposition. American Institute of Aeronautics and Astronautics.

Gilichinsky, D.A., Wilson, G.S., Friedmann, E.I., McKay, C.P., Sletten, R.S., Rivkina, E.M., Vishnivetskaya, T.A., Erokhina, L.G., Ivanushkina, N.E., Kochkina, G.A., Shcherbakova, V.A., Soina, V.S., Spirina, E.V., Vorobyova, E.A., FyodorovDavydov, D.G., Hallet, B., Ozerskaya, S.M., Sorokovikov, V.A., Laurinavichyus, K.S., Shatilovich, A., Chanton, J.P., Ostroumov, V.E., Tiedje, J.M., 2007. Microbial populations in Antarctic permafrost: biodiversity, state, age, and implication for astrobiology. Astrobiology 7 (2), 275-311.

Godon, P., Jugie, G., Frenot, Y., Cucinotta, A., 2007. Concordia: the new permanent research support facility on the antarctic plateau. In: Epchtein, N., Candidi, M. (Eds.), 1st ARENA Conference on Large Astronomical Infrastructures at CONCORDIA, Prospects and Constraints for Antarctic Optical/IR Astronomy. EAS Publications Series, vol. 25, Roscoff, France, October 16-19, 2006, pp. 7-11.

Graziosi, D., Stein, J., Ross, A., Kosmo, J., 2001. Phase VI advanced EVA glove development and certification for the international space station. In: Proceedings of the 31st International Conference on Environmental Systems. No. 2001-01-2163. Society of Automotive Engineers, pp. 1-8.

Harris, G., 2001. The Origins and Technology of the Advanced Extravehicular Space Suit. American Astronautical Society, San Diego, CA.

Heldmann, J., McKay, C.P., Coe, L., 2007. Spaceward bound: training and inspiring the next generation of space explorers. In: Proceedings of the 7th Australian
Mars Exploration Conference. Mars Society Australia, Perth, Western Australia, July, pp. 1-7.

Herbert, G. 1993. Systems for EMU Mars design. In: Boston, PJ. (Ed.), The Case for Mars V: Proceedings of the Fifth Case for Mars Conference. Science and Technology Series, vol. 97. American Astronautical Society, May, pp. 187-194.

Jones, E.M., Schmitt, H.H., 1992. Pressure suit requirements for Moon and Mars EVAs. In: Engineering, Construction and Operations in Space III. No. LA-UR-913083. American Society of Civil Engineers, Denver, CO, pp. 1701-1708.

Laing, J.H., Clarke, J., Deckert, J., Gostin, V., Hoogland, J., Lemke, L., Leyden, J., Mann, G., Murphy, G., Stoker, C., Thomas, M., Waldie, J., Walter, M., West, M.D., 2004. Using an Australian Mars Analogue Research facility for astrobiology, education and outreach. In: Norris, R.P., Stootman, F.H. (Eds.), Bioastronomy 2002: Life Among the Stars. No. 213. International Astronomical Union, Astronomical Society of the Pacific, San Francisco, CA, pp. 553-558.

Laing, J.H., Jenkyns, R., Karouia, F., 2006. PR or perish? Promotion and outreach opportunities in Mars analogue research. In: Clarke, J.D.A. (Ed.), Mars Analog Research. Science and Technology Series, vol. 111. American Astronautical Society, San Diego, CA, pp. 39-52.

Lee, P., Osinski, G.R., 2005. The Haughton-Mars project: overview of science investigations at the Haughton impact structure and surrounding terrains, and relevance to planetary studies. Meteoritics \& Planetary Science 40 (12), 1755-1758.

Lugg, D., 1994. Antarctica as a space laboratory. In: Hempel, G. (Ed.), Antarctic Science-Global Concerns. Springer, Berlin, Germany, pp. 229-242 Antarctic Science Conference, Bremen, Germany, September, 1991.

Lugg, D., 2005. Behavioral health in Antarctica: implications for long-duration space missions. Aviation Space and Environmental Medicine 76 (6, Suppl. S), B74-B77.

Lugg, D., Shepanek, M., 1999. Space analogue studies in Antarctica. Acta Astronautica 44 (7-12), 693-699 (special issue).

Mann, G.A., 2004. Trials and tribulations of the Starchaser Marsupial Rover. In: Proceedings of the 4th Australian Mars Exploration Conference. Mars Society Australia, University of South Australia.

Mann, G.A., 2006. Design, construction and test operations of an analog pressurised planetary exploration vehicle. In: Clarke, J.D.A. (Ed.), Mars Analog Research. Science and Technology Series, vol. 111. American Astronautical Society, pp. 237-252.

Mann, G.A., Clarke, J.D.A., Gostin, V.A., 2004a. Surveying for Mars analogue research sites in the central Australian deserts. Australian Geographical Studies 30, 116-124.

Mann, G.A., Wood, N.B., Clarke, J.D.A., Piechocinski, S., Bamsey, M., Laing, J.H., 2004b. Comparative field tests of pressurised rover prototypes. In: Cockell, C.S. (Ed.), Mars Expedition Planning. Science and Technology Series, vol. 107. American Astronautical Society, pp. 313-325, Meeting on Martian Expedition Planning, London, England, February 24, 2003.

Mann, G.A., Wood, N.B., Clarke, J.D.A., Piechocinski, S., Bamsey, M., Laing, J.H., 2004c. Comparative field tests of pressurised rover prototypes. Journal of the British Interplanetary Society 57 (3/4), 135-143.

Newman, D., 2000. Life in extreme environments: How will humans perform on Mars?. ASGSB Gravitational Space Biology Bulletin 13 (2), 35-47.

Newman, D., Barrat, M., 1997. Life support and performance issues for extravehicular activity (EVA). In: Churchill, S.E., Oser, H. (Eds.), Fundamentals of Space Life Sciences, vol. 2. Krieger Publishing Company (Chapter 23).

O'Hara, J.M., Briganti, M., Cleland, J., Winfield, D., 1998. Extravehicular Activities Limitations Study, Establishment of Physiological and Performance Criteria for EVA Gloves, vol. II. CR 172099, National Aeronautics and Space Administration.

Oliver, C.A., 2007. The virtual space exploration education portal. Acta Astronautica $61,548-552$

Oliver, C.A., 2008. Communicating astrobiology in public: a study of scientific literacy. Ph.D. Thesis, University of New South Wales, Sydney, Australia.

Oliver, C.A., Fergusson, J., Bruce, G., Gaskins, T., 2006. The NASA-Macquarie University Pilbara Education Project: connecting the public to 'science in the making' via virtual reality and the Internet. AGU Fall Meeting Abstracts (ED53C-02), C2.

Osburg, J., Sipes, W., Fieldler, E., 2003. The MEOW experiment: measuring cognitive performance of planetary analog base crewmembers. In: Proceedings of the International Conference on Environmental Systems. Society of Automotive Engineers.

Paulson, A., Green, W., Rowland, C., 2004. Analog pressurized Mars rover design. In: Cockell, C.S. (Ed.), Martian Expedition Planning. Science and Technology Series, vol. 107. American Astronautical Society, pp. 299-311, Meeting on Martian Expedition Planning, London, England, February 24, 2003.

Persaud, R., Robles, S., Clarke, J., Dawson, S., Mann, G., Waldie, J., Piechocinski, S., Roesch, J., 2004. Expedition one: a Mars analog research station 30-day mission. In: Cockell, C.S. (Ed.), Martian Expedition Planning. Science and Technology Series, vol. 107. American Astronautical Society, pp. 53-87, Meeting on Martian Expedition Planning, London, England, February 24, 2003.

Scheuring, R.A., Jones, J.A., Novak, J.D., Polk, J.D., Gillis, D.B., Schmid, J., Duncan, J.M., Davis, J.R., 2007. The Apollo Medical Operations Project: Recommendations to Improve Crew Health and Performance for Future Exploration Missions and Lunar Surface Operations. TM 2007-214755, National Aeronautics and Space Administration, Johnson Space Center.

Schmidt, L., Wood, J., Lugg, D., 2005. Gender differences in leader and follower perceptions of social support in Antarctica. Acta Astronautica 56 (9-12), 923-931. 
Schopf, J.W., Kudryavtsev, A.B., Czaja, A.D., Tripathi, A.B., 2007. Evidence of archean life: stromatolites and microfossils. Precambrian Research 158 (3-4), 141-155.

Shearer, W., Lee, B., Cron, S., Rosenblatt, H., Smith, E., Lugg, D., Nickolls, P., Sharp, R. Rollings, K., Reuben, J., 2002. Suppression of human anti-inflammatory plasma Cytokines IL-10 and IL1-RA with elevation of proinflammatory (Cytotoxic) cytokine IFN-gamma in the antarctic winter-over model of space flight. Clinical Immunology 103 (3, Part 2, Suppl. S), S3-S4.

Shearer, W., Lugg, D., Rosenblatt, H., Nickolls, P., Sharp, R., Reuben, J., Ochs, H., 2001. Antibody responses to bacteriophage phi X-174 in human subjects exposed to the Antarctic winter-over model of spaceflight. Journal of Allergy and Clinical Immunology 107 (1), 160-164.

Shepherd, C., Lednicky, C., 1990. EVA Gloves: History, Status and Recommendations for Future NASA Research. JSC 23733, Lockheed Engineering and Sciences Company.

Sorenson, E.A., Sanner, R.M., Ranniger, C.U., 1997. Experimental testing of a powerassisted space suit glove joint. In: Proceedings of IEEE International Conference on Systems, Man, and Cybernetics. vols. 1-5. IEEE, New York, pp. 2619-2625.

Spencer, P., Pakakis, M., Thompson, L.A., Mathers, N.M., 2005. Victorian Space Science Education Centre: a science launch platform for young Australians. In: Proceedings of the 5th Australian Space Science Conference. National Space Society of Australia, Melbourne, Australia, pp. 411-413.

Storrie-Lombardi, M.C., Brown, A.J., Walter, M.R., 2004. Remote and in situ detection of environmental and biological signatures: ground-truthing hyperspectral imaging for planetary exploration. In: Hoover, R.B., Levin, G.V., Rozanov, A.Y. (Eds.), Conference on Instruments, Methods, and Missions for Astrobiology VIII, vol. 5555, pp. 270-280

Strauss, S., Krog, R.L., Feiveson, A.H., 2005. Extravehicular mobility unit training and astronaut injuries. Aviation Space and Environmental Medicine 76 (5), 469-474.

Suedfeld, P., 2010. Historical space psychology: early terrestrial explorations as Mars analogues. Planetary and Space Science 58 (4), 639-645.

Suedfeld, P., Weiss, K., 2000. Antarctica—natural laboratory and space analogue for psychological research. Environment and Behavior 32 (1), 7-17.

Tafforin, C., 2005. Ethological indicators of isolated and confined teams in the perspective of missions to Mars. Aviation Space and Environmental Medicine 76 (11), 1083-1087.

Tanaka, K., Waldie, J., Steinbach, G., Webb, P., Tourbier, D., Knudsen, J., Jarvis, C., Hargens, A., 2002. Skin microvascular flow and finger girth with and without a mechanical counter pressure space suit glove. FASEB Journal 16 (4, Part 1), A46.

Thomas, M., Brown, A.J., Walter, M.R., Cudahy, T.J., 2002. Applications of hyperspectral analysis to mapping Precambrian hydrothermal alteration systems in Australia. In: Proceedings of Society of Economic Geologists Conference: Predictive Mineral Discovery Under Cover. Perth, Western Australia.

Thomas, M. Clarke, J.D.A., Pain, C.F., 2005. Weathering, erosion and landscape processes on Mars identified from recent rover imagery, and possible Earth analogues. Australian Journal of Earth Sciences 52 (3), 365-378.

Thomas, M., Walter, M.R., 2002. Application of hyperspectral infrared analysis of hydrothermal alteration on Earth and Mars. Astrobiology 2 (3), 335-351.
Tingate, T., Lugg, D., Muller, H., Stowe, R., Pierson, D., 1997. Antarctic isolation: immune and viral studies. Immunology and Cell Biology 75 (3), 275-283.

Van Kranendonk, M.J. 2006. Volcanic degassing hydrothermal circulation and the flourishing of early life on Earth: a review of the evidence from c. 3490-3240 Ma rocks of the Pilbara Supergroup, Pilbara Craton, Western Australia. EarthScience Reviews 74 (3-4), 197-240.

Waldie, J., Tanaka, K., Tourbier, D., Webb, P., Jarvis, C., Hargens, A., 2002. Compression under a mechanical counter pressure space suit glove. Journal of Gravitational Physiology 9 (2), 93-97.

Waldie, J.M.A., 2005. The viability of mechanical counter pressure space suits. Ph.D. Thesis, Royal Melbourne Institute of Technology, Melbourne, Australia.

Waldie, J.M.A., Cutler, N.A., 2006. The flexibility of mechanical counter pressure space suit gloves. In: Clarke, J.D.A. (Ed.), Mars Analog Research. Science and Technology Series, vol. 111. American Astronautical Society, pp. 161-174.

Waldie, J.M.A., Wisely, D., Ischia, D., Harvey, B., 2002. MarsSkin: a mechanical counter pressure Mars analogue space suit. In: Clarke, J.D.A., Murphy, G., West, M.D. (Eds.), Proceedings of the 2nd Australian Mars Exploration Conference. Mars Society Australia, University of Sydney, Sydney, Australia.

Walter, M.R., Buick, R., Dunlop, J.S.R., 1980. Stromatolites 3,400-3,500 MYR old from the north-pole area, Western Australia. Nature 284 (5755), 443-445.

Welsh, M.H., Akin, D.L., 2001. The effects of extravehicular activity gloves on human hand performance. In: Proceedings of the 31st International Conference on Environmental Systems. No. 2001-01-2164. Society of Automotive Engineers, pp. 1-8.

West, M.D., Clarke, J.D.A., 2010. Potential martian mineral resources: mechanisms and terrestrial analogues. Planetary and Space Science 58 (4), 574-582.

West, M.D., Clarke, J.D.A., Thomas, M., Pain, C.F., Walter, M.R., 2010. The geology of Australian Mars analogue sites. Planetary and Space Science 58 (4), 447-458.

Willson, D., Clarke, J.D.A., 2005. A proposed Mars base design adopting a horizontally landed bent biconic vehicle. Journal of the British Interplanetary Society 58 (5-6), 181-196.

Willson, D., Clarke, J.D.A., 2006. A practical architecture for exploration-focused manned Mars missions using chemical propulsion, solar power generation and in-situ resource utilisation. In: Proceedings of the 6th Australian Space Science Conference. National Space Society of Australia, Canberra, pp. 186-211.

Willson, D., Clarke, J.D.A., Murphy, G., 2005. MARS-Oz: a design for a simulated Mars base in the Australian outback. Journal of the British Interplanetary Society 58 (9-10), 282-293.

Wood, J., Lugg, D., Hysong, S., Harm, D., 1999. Psychological changes in hundred-day remote Antarctic field groups. Environment and Behavior 31 (3), 299-337.

Wood, J., Schmidt, L., Lugg, D., Ayton, J., Phillips, T., Shepanek, M., 2005. Life survival, and behavioral health in small closed communities: 10 years of studying isolated antarctic groups. Aviation Space and Environmental Medicine 76 (6, Suppl. S), B89-B93.

Zubrin, R.M., Baker, D.A., 1992. Mars direct-humans to the Red Planet by 1999 Acta Astronautica 26 (12), 899-912. 